\title{
Multi-frequency bioelectric impedance measurements for predicting body water compartments in patients with non-ascitic liver cirrhosis
}

\author{
BY A. BORGHI ${ }^{1}$, G. BEDOGNI ${ }^{2}$, E. ROCCHI ${ }^{1}$, S. SEVERI ${ }^{2}$, F. FARINA $^{1}$ \\ AND N. BATTISTINI ${ }^{2 *}$ \\ ${ }^{1}$ Department of Internal Medicine, Medicine Clinic III, University of Modena, Via del Pozzo, \\ 41100, Modena, Italy \\ ${ }^{2}$ Department of Biomedical Sciences, Institute of Human Physiology, University of Modena, \\ Via Campi 287, 41100, Modena, Italy
}

(Received 1 March 1995 - Revised 9 May 1995 - Accepted 20 December 1995)

\begin{abstract}
We assessed total body water (TBW) and extracellular water (ECW) in thirty-four non-ascitic cirrhotics and twenty healthy controls by ${ }^{2} \mathrm{H}_{2} \mathrm{O}$ and $\mathrm{Br}$ dilution. In the same subjects, bioelectric impedance (BI) was recorded at multiple frequencies. Body hydration was similar for controls (mean 55.6 (SD 6.7)), lesssevere cirrhotics (Child-Pugh classification A; CPA; $n$ 21, mean 56.2 (SD 6.2)) and moderately-severe cirrhotics (Child-Pugh classification B; CPB; $n$ 13, mean 57.2 (SD 5.4)). However, intracellular water standardized per litre TBW was significantly higher in CPB subjects (mean 27.0 (SD 7.5); $P<0.01$ ) compared with CPA (mean 21.3 (SD 10.6)) and control subjects (mean 18.0 (SD 9.8)). Published formulas for predicting TBW and ECW from BI at multiple frequencies were applied to the cirrhotics. These formulas gave accurate predictions of TBW and ECW, although standard errors of estimates were higher for CPB subjects (TBW $\leqslant 2.5$ and ECW $\leqslant 2.1$ l) than those for CPA (TBW $\leqslant 2.0$ and ECW $\leqslant$ 1.8 l) and control (TBW 1.4 and ECW 0.9 l) subjects.
\end{abstract}

Liver cirrhosis: Total body water: Extracellular water: Bioelectric impedance

Assessment of body water compartments is of great clinical interest. Body hydration and extracellular water (ECW):intracellular water (ICW) ratio are known to change with nutritional status and under a variety of disease conditions. Malnourished patients often exhibit an increase in ECW relative to total body water (TBW; Rose 1994b). Nonetheless, obese subjects often show an increase in ECW relative to TBW, the pathophysiological basis of which is currently under investigation (Waki et al. 1991; Battistini et al. 1995). In addition to under- and overweight states, it has been shown that an increase in ECW relative to TBW may occur also in highly-trained athletes (Battistini et al. 1994). Thus, body-water distribution appears to be significantly linked to nutritional status in both physiological and clinical conditions.

Measurements of TBW and ECW involve the use of invasive and time-consuming tracerdilution techniques and, therefore, are not suitable for use in clinical practice. Multifrequency bioelectric impedance analysis (MFBIA) is a novel technique for the assessment of TBW and ECW (van Marken Lichtenbelt et al. 1994). MFBIA has many advantages over dilution methods in that it is safe, inexpensive, portable and requires minimal training of the operator. Thus, MFBIA has a great potential to be employed as a 'bedside' technique for assessing body water volumes in ill subjects.

$$
\text { * For reprints. }
$$


Water retention is common in the later stages of liver cirrhosis (Schober et al. 1979; McCullough et al. 1991; Zillikens et al. 1992a; Crawford et al. 1993; Prijatmoko et al. 1994). The increase in TBW is largely due to an expansion of extracellular water (ECW; McCullough et al. 1991; Crawford et al. 1993) which may become clinically apparent in the form of oedema or ascites. However, ICW may be expanded also and contribute to the overall increase in TBW (Schober et al. 1979). In cirrhotics with ascites, single-frequency bioelectric impedance analysis (BIA) does not allow an accurate estimate of TBW and ECW (McCullough et al. 1991; Zillikens et al. 1992 b; Prijatmoko et al. 1994). Although some studies of BIA have been performed in non-ascitic cirrhotic patients, they have focused on the use of a single frequency $(50 \mathrm{kHz}$; Zillikens et al. $1992 a$ ) and have given unsatisfactory results for the prediction of ECW (McCullough et al. 1991).

The aim of the present study was to assess the accuracy of MFBIA for predicting TBW and ECW of non-ascitic cirrhotics.

\section{MATERIALS AND METHODS}

\section{Subjects}

Thirty-four male cirrhotic patients with no clinical or ultrasonographic evidence of ascites or oedema were enrolled in the study. Twenty healthy subjects of the same age were recruited as controls. Informed consent was obtained from all the subjects taking part in the study. The experimental protocol had been previously approved by the Ethical Committee at the University of Modena. Patients were classifiable in classes A (CPA, $n$ 13) and $B$ (CPB, $n$ 21) of Child-Pugh; the classification of Child-Pugh being based on the values for five variables (serum albumin and bilirubin, prothrombin time, degree of ascites and encephalopathy) which identify three progressively worsening stages of cirrhosis: A, B and $\mathrm{C}$. None of the enrolled patients had experienced water retention (oedema and ascites) or other major complications of the underlying disease (e.g. encephalopathy or gastrooesophageal bleeding). Histological diagnosis was performed in all cases. The ætiology of liver cirrhosis was viral, alcoholic or mixed. None of the patients or controls had taken any drug for at least 1 month before the study, except vitamin $\mathrm{K}$ in some cirrhotic subjects. For at least 1 week beforehand, both patients and controls had been on a standard hospital diet, which adequately covers protein and energy requirements, but without $\mathrm{Na}$ restriction. All cirrhotics had abstained from alcohol for at least 12 months.

\section{TBW and ECW assessment}

TBW and ECW were measured by ${ }^{2} \mathrm{H}_{2} \mathrm{O}$ and $\mathrm{NaBr}$ dilution respectively. Subjects fasted for at least $12 \mathrm{~h}$ and voided the bladder before receiving orally a precisely weighed solution made up of ${ }^{2} \mathrm{H}_{2} \mathrm{O}, \mathrm{NaBr}$ and drinking water. A preliminary study aimed at establishing the time needed by ${ }^{2} \mathrm{H}_{2} \mathrm{O}$ and $\mathrm{Br}$ to reach equilibrium was done on the plasma of five unselected cirrhotic patients. Both tracers reached equilibrium $2.5 \mathrm{~h}$ after their administration, a time similar to that for healthy subjects (Lukaski \& Johnson, 1985) and very close to that obtained by others for TBW (McCullough et al. 1991; Prijatmoko et al. 1994; Zillikens et al. 1992a) and ECW (Crawford et al. 1993; McCullough et al. 1991) of nonascitic cirrhotics. Following this finding, blood samples for ${ }^{2} \mathrm{H}_{2} \mathrm{O}$ and $\mathrm{Br}$ measurements were taken just before the tracer load and $3.5 \mathrm{~h}$ later in both cirrhotic and control subjects. A detailed description of ${ }^{2} \mathrm{H}_{2} \mathrm{O}-\mathrm{Br}$ load and body fluid collection is given elsewhere (Battistini et al. 1992, 1994). The ${ }^{2} \mathrm{H}_{2} \mathrm{O}$ load was sufficient to increase the isotopic excess to approximately $500 \% \delta$ units over the background. ${ }^{2} \mathrm{H}_{2} \mathrm{O}$ enrichment in plasma samples was measured by FT-IR spectrophotometry according to the method of Lukaski \& Johnson (1985). TBW was calculated as ${ }^{2} \mathrm{H}_{2} \mathrm{O}$ dilution space $\times 0.95$, taking into account non-aqueous 
distribution of ${ }^{2} \mathrm{H}_{2} \mathrm{O}$. Br concentration in plasma was measured by HPLC according to the method of Wong et al. (1989). ECW was calculated as $\mathrm{Br}$ dilution space $\times 0.90 \times 0.95$ taking into account non-extracellular distribution of $\mathrm{Br}$ and Donnan's effect respectively. The final concentration in plasma was below one-tenth of the value regarded as toxic (6 mM; Goodman \& Gillman 1970). Duplicate measurements were performed to assess measurement precision which proved to be 2.0 and $1.5 \%$ for ${ }^{2} \mathrm{H}_{2} \mathrm{O}$ and $\mathrm{Br}$ respectively. ICW was calculated as the difference between TBW and ECW.

\section{Anthropometry}

Weight and height were measured to the nearest $0.1 \mathrm{~kg}$ and $0.005 \mathrm{~m}$ respectively, with the subjects wearing only light cotton clothes. Triceps skinfold thickness and arm circumference were measured following the directions of the Anthropometric Standardization Reference Manual (Lohman et al. 1988). BMI was calculated as weight $(\mathrm{kg}) / \mathrm{height}^{2}(\mathrm{~m})$. Arm fat area (AFA) and arm muscle area (AMA) were calculated as described by Frisancho (1990). The calculation of creatinine-height index (CHI) was based on three consecutive determinations of the $24 \mathrm{~h}$ urinary creatinine. CHI was regarded as an index of FFM, following the results of previous studies in cirrhotics (Rocchi et al. 1991; Kondrup et al. 1992; Nielsen et al. 1993).

\section{$M F B I A$}

The determination of bioelectric impedance $(Z)$ was made with a tetrapolar impedance plethysmograph (Human-IM Scan; Dietosystem, Milan, Italy) at frequencues of 1, 5 and $100 \mathrm{kHz}$. Current-injecting electrodes were placed on the dorsal surfaces of the hand and foot proximal to metacarpal-phalangeal and metatarsal-phalangeal joints respectively, and voltage-sensing electrodes were placed between wrist and ankle, as described in detail by Lukaski et al. (1985). The reproducibility of measurements was: between 1 and $3 \Omega$ $(0 \cdot 1-0.4 \%)$ at lower frequencies, and between 2 and $4 \Omega(0.3-0.6 \%)$ at $100 \mathrm{kHz}$. TBW was calculated from the impedance index $\left(\mathrm{ZI}\right.$; height $\left.{ }^{2} / \mathrm{Z}\right)$ at $100 \mathrm{kHz}\left(\mathrm{ZI}_{100}\right)$ by applying the formulas of Deurenberg et al. (1993) and Segal et al. (1991). ZI were also calculated at frequencies of $1\left(\mathrm{ZI}_{1}\right)$ and $5\left(\mathrm{ZI}_{5}\right) \mathrm{kHz}$ to predict $\mathrm{ECW}$, as described by Deurenberg et al. (1993) and Segal et al. (1991) respectively. The Segal et al. (1991) formulas do employ bioelectric resistance $(R)$ instead of $Z$ and include body weight. In a study on healthy subjects we found that substituting $R$ with $Z$ at frequencies of 5 and $100 \mathrm{kHz}$ does not modify the accuracy of the prediction of ECW and TBW obtained by the Segal et al. (1991) equations (A. Borghi, G. Bedogni, E. Rocchi, S. Severi, F. Farina and N. Battistini, unpublished results). Therefore, $Z$ was used instead of $R$ for predicting TBW and ECW from the Segal et al. (1991) equations in the present study.

\section{Statistical analysis}

Statistical analysis (means and standard deviations, one-way ANOVA and regressions) was performed using a Macintosh computer with the Statview 4.01 software package (Abacus Concepts Inc., 1992). The level of significance was set to a value of $P<0.05$.

\section{RESULTS}

The main characteristics of control and cirrhotic subjects are given in Table 1. Controls and patients were matched for age. Body weight, BMI, AFA and AMA, and CHI were all significantly lower in CPB subjects than in CPA and control subjects (Table 1).

As an absolute value, TBW was lower in CPB subjects than in CPA and control subjects (Table 2). However, when standardized on a per kg body weight basis, TBW was similar in patients and controls (Table 1). ECW showed a downward trend from controls to CPA 
Table 1. Main characteristics of control and cirrhotic subjects $\$$ in Child-Pugh classifications $A(C P A)$ and $B(C P B) \dagger$

(Mean values and standard deviations)

\begin{tabular}{|c|c|c|c|c|c|c|}
\hline \multirow[t]{2}{*}{$n \ldots$} & \multicolumn{2}{|c|}{$\begin{array}{c}\text { Controls } \\
20\end{array}$} & \multicolumn{2}{|c|}{$\begin{array}{c}\text { CPA } \\
21\end{array}$} & \multicolumn{2}{|c|}{$\begin{array}{c}\text { CPB } \\
13\end{array}$} \\
\hline & Mean & SD & Mean & SD & Mean & SD \\
\hline Age (years) & $50 \cdot 5$ & 11.9 & 56.6 & $7 \cdot 4$ & $55 \cdot 6$ & $10 \cdot 4$ \\
\hline Wt $(\mathrm{kg})$ & $78 \cdot 4 * *$ & $11 \cdot 1$ & $73 \cdot 1 * *$ & $8 \cdot 1$ & $66 \cdot 7$ & $14 \cdot 9$ \\
\hline Height (m) & $1.72 \dagger$ & 0.08 & 1.65 & 0.06 & 1.67 & 0.11 \\
\hline $\mathrm{BMI}\left(\mathrm{kg} / \mathrm{m}^{2}\right)$ & $26 \cdot 6^{*}$ & $4 \cdot 4$ & $27 \cdot 0^{*}$ & $2 \cdot 3$ & 23.9 & $3 \cdot 7$ \\
\hline $\mathrm{AMA}\left(\mathrm{mm}^{2}\right)$ & $70 \cdot 2^{* *}$ & $13 \cdot 7$ & $67 \cdot 4 * *$ & $9 \cdot 4$ & $51 \cdot 6$ & 13.0 \\
\hline AFA $\left(\mathrm{mm}^{2}\right)$ & $12 \cdot 4$ & $4 \cdot 8$ & 11.8 & 3.9 & $9 \cdot 3$ & 1.0 \\
\hline $\mathrm{CHI}$ & $0.85^{* *}$ & $0 \cdot 18$ & $0.78 * *$ & $0 \cdot 16$ & $0 \cdot 60$ & 0.13 \\
\hline TBW $\%$ & $55 \cdot 6$ & $6 \cdot 7$ & $56 \cdot 2$ & $6 \cdot 2$ & $57 \cdot 2$ & 5.4 \\
\hline $\mathrm{ECW} \%$ & $37 \cdot 6^{* *}$ & $3 \cdot 2$ & $34 \cdot 9^{* *}$ & 49 & $30 \cdot 2$ & 3.0 \\
\hline ICW $\%$ & $180^{* *}$ & 9.8 & $21 \cdot 3 * *$ & $10 \cdot 6$ & $27 \cdot 0$ & $7 \cdot 5$ \\
\hline ECW : ICW & $0.60 * * *$ & $0-08$ & $0.56 * * *$ & $0 \cdot 14$ & 0.43 & 0.06 \\
\hline
\end{tabular}

BMI, body mass index; AMA, arm muscle area; AFA, arm fat area; CHI, creatinine-height index; TBW \%, total body water standardized on a per $\mathrm{kg}$ body weight basis; ECW\%, extracellular water standardized on a per litre total body water basis; ICW \%, intracellular water standardized on a per litre total body water basis; $\mathrm{ECW}: \mathrm{ICW}$, extracellular:intracellular water.

Mean values were significantly different from those for CPB subjects: $* P<0.05,{ }^{* *} P<0.01, * * * P<0.001$.

Mean values were significantly different from those for CPA subjects: $\dagger P<0.05$.

For details, see p. 326.

$\$$ The Child-Pugh classification is based on values for serum albumin and bilirubin, prothrombin time, degree of ascites and encephalopathy, which identifies three progressively worsening stages of cirrhosis: A, B and C.

Table 2. Total body water (litres) assessed by ${ }^{2} \mathrm{H}_{2} \mathrm{O}$ dilution and predicted by multi-frequency bioelectric impedance analysis (MFBIA) following application of the Deurenberg et al. (1993; $M F B I A-D)$ and Segal et al. (1991; MFBIA-S) formulas for controls, and Child-Pugh classification $\ddagger A(C P A)$ and $B(C P B)$ subjects $\ddagger$

(Mean values and standard deviations)

\begin{tabular}{|c|c|c|c|c|c|c|c|}
\hline & \multirow[b]{2}{*}{$n$} & \multicolumn{2}{|c|}{${ }^{2} \mathrm{H}_{2} \mathrm{O}$ dilution } & \multicolumn{2}{|c|}{ MFBIA-D } & \multicolumn{2}{|c|}{ MFBIA-S } \\
\hline & & Mean & $\mathrm{SD}$ & Mean & $\mathrm{SD}$ & Mean & SD \\
\hline Controls & 20 & $43 \cdot 2^{*}$ & $5 \cdot 0$ & $44 \cdot 3 \dagger$ & 4.6 & $44 \cdot 1 \dagger$ & $4 \cdot 6$ \\
\hline CPA & 21 & $41 \cdot 1^{*}$ & $6 \cdot 3$ & $42.7 \dagger$ & $5 \cdot 0$ & $42 \cdot 5 \dagger$ & $5 \cdot 5$ \\
\hline $\mathrm{CPB}$ & 13 & $37-9$ & $7 \cdot 7$ & $39.5 \dagger$ & 5.6 & $39 \cdot 4 \dagger$ & $5 \cdot 1$ \\
\hline
\end{tabular}

Mean values were significantly different from those for CPB subjects: ${ }^{*} P<0.05$.

$\dagger$ Mean values were not significantly different from those obtained by ${ }^{2} \mathrm{H}_{2} \mathrm{O}$ dilution.

\$ For details of subjects and procedures, see Table 1 and pp. 326-327 respectively.

and CPB patients (Table 3) but, when standardized per litre TBW, ECW was lower in CPB subjects than in CPA and control subjects $(P<0.01$; Table 1$)$. As an absolute amount, ICW was similar in CPA (mean 27.0 (SD 5.6)), CPB (mean 26.5 (SD 5.9)) and control subjects (mean 27.0 (sD 3.8)). However, expressed as a percentage of TBW, ICW was higher in CPB subjects than in CPA and control subjects $(P<0.01$; Table 1$)$. It follows that the 
Table 3. Extracellular water (litres) assessed by bromide dilution and predicted by multifrequency bioelectric impedance analysis (MFBIA) following application of the Deurenberg et al. $(1993 ; M F B I A-D)$ and Segal et al. $(1991 ; M F B I A-S)$ formulas for controls, and Child-Pugh classification§ $A(C P A)$ and $B(C P B)$ subjects§

(Mean values and standard deviations)

\begin{tabular}{|c|c|c|c|c|c|c|c|}
\hline & \multirow[b]{2}{*}{$n$} & \multicolumn{2}{|c|}{ Br dilution } & \multicolumn{2}{|c|}{ MFBIA-D } & \multicolumn{2}{|c|}{ MFBIA-S } \\
\hline & & Mean & SD & Mean & $\mathrm{SD}$ & Mean & SD \\
\hline Controls & 20 & $16 \cdot 2^{* * *+1+\dagger}$ & 1.9 & $16 \cdot 3 \ddagger$ & 1.7 & $16 \cdot 3 \ddagger$ & 1.7 \\
\hline CPA & 21 & $14 \cdot 1^{* * *}$ & $1 \cdot 7$ & $14 \cdot 3 \ddagger$ & $2 \cdot 6$ & $14 \cdot 3 \ddagger$ & $1 \cdot 7$ \\
\hline CPB & 13 & $11 \cdot 4$ & $2 \cdot 1$ & $11 \cdot 7 \ddagger$ & $3 \cdot 5$ & $11 \cdot 6 t$ & $3 \cdot 0$ \\
\hline
\end{tabular}

Mean values were significantly different from those for CPB subjects: $* * * P<0 \cdot 001$.

Mean value was significantly different from that for CPA subjects: $\dagger^{\dagger} \dagger P<0.001$.

$\ddagger$ Mean values were not significantly different from those obtained by dilution.

$\S$ For details of subjects and procedures, see Table 1 and pp. $326-327$ respectively.

Table 4. Correlation coefficients $(r)$ and standard errors of the estimate (SEE) for the regression of total body water $(T B W)$ and extracellular water $(E C W)$ measured by dilution v. the respective values obtained by MFBIA following applications of the Deurenberg et al. $(1993 ; D)$ and Segal et al. $(1991 ; S)$ formulas for controls and Child-Pugh classification $A$ $(C P A)$ and $B(C P B)$ subjects*

\begin{tabular}{|c|c|c|c|c|c|c|c|c|}
\hline & \multicolumn{2}{|c|}{ TBW-D } & \multicolumn{2}{|c|}{ TBW-S } & \multicolumn{2}{|c|}{ ECW-D } & \multicolumn{2}{|c|}{ ECW-S } \\
\hline & $r$ & SEE & $r$ & SEE & $r$ & SEE & $r$ & SEE \\
\hline Controls & 0.902 & 1.4 & 0.904 & 1.4 & 0.850 & 0.90 & 0.853 & 0.90 \\
\hline CPA & 0.890 & 2.0 & 0.901 & 1.8 & 0.820 & 1.8 & 0.850 & 1.6 \\
\hline CPB & 0.860 & $2 \cdot 4$ & 0.905 & $2 \cdot 5$ & 0.788 & $2 \cdot 1$ & 0.804 & $2 \cdot 0$ \\
\hline
\end{tabular}

All values for $r$ were significant $(P<0.001)$.

* For details of subjects and procedures, see Table 1 and pp. $326-327$ respectively.

ECW:ICW value was significantly lower in CPB subjects than in CPA and control subjects $(P<0.001$; Table 1$)$.

The values for TBW and ECW obtained by dilution were compared with those predicted by MFBIA using the formulas of Deurenberg et al. (1993) and Segal et al. (1991). Measured and predicted values of TBW and ECW were not significantly different for both controls and cirrhotics (Tables 2 and 3). Correlation coefficients and standard errors of estimates (SEE) for predicted $v$. measured values were slightly higher for CPA and CPB subjects as compared with control subjects (Table 4). However, the employed formulas allowed a satisfactory prediction of TBW and ECW in both controls and cirrhotics.

\section{DISCUSSION}

MFBIA has many advantages over dilution methods in that it is safe, inexpensive, portable and requires minimal training of the operator. Based on these characteristics, MFBIA appears to be the ideal technique for the routine assessment of TBW and ECW (van 
Marken Lichtenbelt et al. 1994). However, relatively few studies of MFBIA have been performed on ill subjects and its ability to serve as a 'bedside' technique remains to be determined.

In the present study we assessed the accuracy of the MFBIA method in predicting TBW and ECW of non-ascitic cirrhotic patients. The use of BIA at a single frequency had been shown previously to produce inaccurate estimates of TBW and ECW in cirrhotics with ascites (McCullough et al. 1991; Zillikens et al. 1992b; Prijatmoko et al. 1994). It was shown also that BIA at a single frequency adequately predicts TBW in non-ascitic cirrhotics (Zillikens et al. 1992a). However, in one report, single-frequency BIA failed to predict ECW accurately in non-ascitic cirrhotics (McCullough et al. 1991).

Based on the results of the present study, it appears that algorithms generated on healthy subjects might be utilized satisfactorily for predicting TBW and ECW from MFBIA in nonascitic cirrhotics. ECW: ICW ratio is a factor known to limit the applicability of predictive equations generated by BIA to external populations (Heitmann, 1994). It is of interest, therefore, that our CPB patients had reasonably good predicted values for TBW and ECW from MFBIA in spite of their altered ECW:ICW ratio. Bioelectric techniques do not allow an accurate assessment of TBW and ECW when body water compartmentalization is undergoing acute changes (Battistini et al. 1993; De Lorenzo et al. 1994). However, our findings suggest that MFBIA may allow a satisfactory prediction of TBW and ECW in the presence of a chronically-altered ECW:ICW ratio. The absolute value of the ECW:ICW ratio is very important indeed. In children affected by Duchenne muscle dystrophy with an ECW:ICW ratio of 1.6 , formulas developed for control subjects significantly underscore body water volumes (Bedogni et al. 1996). Our CPB patients had lower correlation coefficients and SEE than CPA and control subjects, thus suggesting that a modified ECW:ICW ratio may reflect, however, on the accuracy of the prediction. It should be noted also that the Segal et al. (1991) equations allowed more accurate prediction of TBW and ECW in cirrhotics than the Deurenberg et al. (1993) formulas. To a lesser extent this was true also for controls (Table 4). This finding is probably explained by the fact that the Segal et al. (1991) equations include body weight along with $\mathrm{ZI}$ among the predictor variables. The use of a formula which includes body weight is questionable when acute changes in water compartments have to be studied (De Lorenzo et al. 1994). However, body weight may allow more accurate prediction of TBW and ECW in the presence of a chronically-altered ECW:ICW ratio which reflects the achievement of a new steady-state (Bedogni et al. 1996).

The increase in percentage ICW for our CPB patients deserves some additional comments. In fact, it is in contrast with the increase in percentage ECW (McCullough et al. 1991) or the constancy of the ECW:ICW ratio (Crawford et al. 1993) shown in other studies. Substantial differences in the selection criteria for enrolled patients (McCullough et al. 1991) and in the techniques employed for estimating ECW (Crawford et al. 1993) might partly explain this difference. The increase in percentage ICW for our CPB patients is nonetheless surprising and suggests that a more complex perturbation of body-water homeostasis occurs in early cirrhosis than is generally accepted. Previous muscle-bioptic studies of cirrhotics have shown that an increase in ICW is almost invariably accompanied by one in intracellular Na (Maschio et al. 1971; Ossi et al. 1974). Based on these studies, one can postulate that a defect in the Na-K ATPase (EC 3.6.1.37) pump may be involved in the disruption of body-water homeostasis in early cirrhosis, similarly to that established for other diseases, such as heart failure and chronic renal failure (Rose 1994a). A longitudinal study is needed to establish the pathophysiological bases for the altered body water distribution which occurs in liver cirrhosis. We should point out, however, that percentage ICW expansion occurs in patients whose nutritional status, as determined by BMI, AMA and CHI, is lower than that of controls and patients at an earlier stage of the 
disease. This finding offers further evidence for the existing link between nutritional status and body-water compartmentalization.

In conclusion, within the scope of the present study it appears that the utilization of MFBIA provides an accurate assessment of body hydration and body-water compartmentalization between extra- and intra-cellular spaces in non-ascitic cirrhotics. This finding may actually facilitate improved clinical management of these patients.

\section{REFERENCES}

Abacus Concepts Inc. (1992). Statview 4.01. Berkeley, CA: Abacus Concepts Inc.

Battistini, N., Brambilla, P., Virgili, F., Simone, P., Bedogni, G., Morini, P. \& Chiumello, G. (1992). The prediction of total body water from body impedance in young obese subjects. International Journal of Obesity 16, 207-211.

Battistini, N., Severi, S., Brambilla, P., Virgili, F., Manzoni, P., Beccaria, L. \& Chiumello, G. (1995). Relative expansion of extracellular water in obese vs non obese children. Journal of Applied Physiology 79, 94-96.

Battistini, N., Virgili, F. \& Bedogni, G. (1994). A relative expansion of extra-cellular water in elite male athletes compared to recreational sportsmen. Annals of Human Biology 21, 609-612.

Battistini, N., Virgili, F., Bedogni, G., Gambella, G. R. \& Bini, A. (1993). In vivo total body water assessment by total body electrical conductivity in rats suffering perturbations of water compartment equilibrium. British Journal of Nutrition 70, 433-438.

Bedogni, G., Merlini, L., Ballestrazzi, A., Severi, S. \& Battistini, N. (1996). Multifrequency bioelectric impedance measurements for predicting body water compartments in Duchenne Muscle Dystrophy. Neuromuscular Disorders 6, 5560 .

Crawford, D. H. G., Halliday, J. W., Cooksley, W. G. E., Murphy, T. L., Golding, S. D., Wallace, J. D., Cuneo, R. C., Lynch, S. V., Strong, R. J. \& Powell, L. W. (1993). Distribution of body water in patients with eirrhosis: the effect of liver transplantation. Hepatology 17, 1016-1021.

De Lorenzo, A., Deurenberg, P., Andreoli, A., Sasso, F. \& Docimo, R. (1994). Multifrequency impedance in the assessment of body water losses during dialysis. Renal Physiology and Biochemistry 17, 326-332.

Deurenberg, P., Schouten, F. J. M., Andreoli, A. \& De Lorenzo, A. (1993). Assessment of changes in extracellular water and total body water using multi-frequency bio-electrical impedance. In Human Body Composition. In Vivo Methods, Models and Assessment, pp. 129-132 [K. J. Ellis and J. D. Eastman, editors]. New York: Plenum Press.

Frisancho, A. (1990). Anthropometric Standards for the Assessment of Growth and Nutritional Status. Ann Arbor, Mich: The University of Michigan Press.

Goodman, L. S. \& Gillman, A. (1970). The Pharmacological Basis of Therapeutics. New York: Macmillan Press.

Heitmann, B. L. (1994). Impedance: a valid method in assessment of body composition? European Journal of Clinical Nutrition 48, 228-240.

Kondrup, J., Nielsen, K. \& Hamberg, O. (1992). Nutritional therapy in patients with liver cirrhosis. British Journal of Nutrition 46, 239-246.

Lohman, T. G., Roche, A. F. \& Martorell, R. (editors) (1988). In Anthropometric Standardization Reference Manual. Champaign, IL: Human Kinetics Books.

Lukaski, H. C. \& Johnson, P. E. (1985). A simple inexpensive method of determining total body water using a tracer dose of deuterium oxide and infrared absorption of biological fluids. American Journal of Clinical Nutrition 41, 363-370.

Lukaski, H. C., Johnson, P. E., Bolonchuck, W. W. \& Lykken, G. I. (1985). Assessment of fat-free mass using bioelectrical impedance measurements of the human body. American Journal of Clinical Nutrition 41, 810-817.

McCullough, A. J., Mullen, K. D. \& Kalhan, S. C. (1991). Measurement of total body and extracellular water in cirrhotic patients with and without ascites. Hepatology 14, 1102-1111.

Maschio, G., D’Angelo, A., Sirigu, F., Ossi, E., Polin, R., Fagiolo, U. \& Naccarato, R. (1971). Muscle biopsies studies in liver cirrhosis. Scandinavian Journal of Gastroenterology 6, 363-367.

Nielsen, K., Kondrup, J., Martinsen, L., Stilling, B. \& Wikman, B. (1993). Nutritional assessment and adequacy of dietary intake in hospitalized patients with alcoholic liver cirrhosis. British Journal of Nutrition 69, 665-679.

Ossi, E., Mioni, G., D’Angelo, A., Lupo, A., Valvo, E. \& Maschio, G. (1974). Aspetti del metabolismo idroelettrolitico indagati con l'agobiopsia muscolare. Reperti nello scompenso cardiaco, nella cirrosi epatica, nel diabete mellito, nell' insufficienza renale cronica (Aspects of water and electrolyte metabolism determined by muscle bioptic studies. Findings in heart failure, liver cirrhosis, diabetes mellitus and chronic renal insufficiency). Giornale di Clinica Medica 55, 131-134.

Prijatmoko, D., Strauss, B. J. G., Lambert, J. R., Sievert, W., Stroud, D. B., Wahlqvist, M. L., Katz, B., Colman, J., Jones, P. \& Korman, M. G. (1994). Early detection of protein depletion in alcoholic cirrhosis: role of body composition analysis. Gastroenterology 105, 1839-1845. 
Rocchi, E., Borghi, A., Paolillo, F., Pradelli, M. \& Casalgrandi, G. (1991). Carotenoids and liposoluble vitamins in liver cirrhosis. Journal of Laboratory and Clinical Medicine 118, 176-185.

Rose, B. D. (1994a). Potassium homeostasis. In Clinical Physiology of Acid-base and Electrolyte Disorders, pp. 346-371. New York: McGraw-Hill.

Rose, B. D. (1994b). Edematous states. In Clinical Physiology of Acid-base and Electrolyte Disorders, pp. $447-499$. New York: McGraw-Hill.

Schober, O., Mariß, P., Schmidt, F. W. \& Hundeshagen, H. (1979). Total body water, extracellular water, plasma volume and total body potassium in cirrhosis of the liver. Kliniks Wochenschrift 57, 757-761.

Segal, K. R., Burastero, S., Chun, A., Coronel, P., Pierson, R. N. \& Wang, J. (1991). Estimation of extracellular and total body water by multiple-frequency bioelectrical-impedance measurements. American Journal of Clinical Nutrition 54, 26-29.

van Marken Lichtenbelt, W., Westerterp, K., Wouters, L. \& Luijendijk, S. (1994). Validation of bioelectricalimpedance measurements as a method to estimate body-water compartments. American Journal of Clinical Nutrition 60, 159-166.

Waki, M., Kral, J., Mazariegos, M., Wang, J., Pierson, R. N. \& Heymsfield, S. B. (1991). Relative expansion of extracellular fluid in obese vs non-obese women. American Journal of Physiology 261, E199-203.

Wong, W. W., Sheng, H. P., Morkenberg, J. C., Kosanovich, J. L., Clarke, L. L. \& Klein, P. D. (1989). Measurement of extracellular water volume by bromide ion chromatography. American Journal of Clinical Nutrition 50, 1290-1295.

Zillikens, M. C., van der Berg, J. W. O., Wilson, J. H. P., Rietveld, T. \& Swart, G. R. (1992a). The validity of bioelectrical impedance analysis in estimating total body water in patients with cirrhosis. Journal of Hepatology 16, 59-65.

Zillikens, M. C., van der Berg, J. W. O., Wilson, J. H. P. \& Swart, G. R. (1992b). Whole-body and segmental bioelectric-impedance analysis in patients with cirrhosis of the liver: changes after treatment of ascites. American Journal of Clinical Nutrition 55, 621-625. 